\title{
Experimental studies of barium titanate nanofibers prepared by electrospinning
}

\author{
M. V. Someswararao ${ }^{1}$, R. S. Dubey ${ }^{2} *$ \\ ${ }^{1}$ Department of Physics, SRKR Engineering College, Bhimavaram, (A.P.), India \\ ${ }^{2}$ Department of Nanotechnology, Swarnandhra College of Engineering and Technology, \\ Seetharampuram, Narsapur (A.P.), India \\ *rag_pcw@yahoo.co.in
}

DOI 10.17586/2220-8054-2019-10-3-350-354

\begin{abstract}
This paper reports the fabrication and characterization of $\mathrm{BaTiO}_{3}$ nanofibers prepared by the electrospinning method. The X-ray diffraction (XRD) pattern revealed the formation of tetragonal phase corresponding to the Bragg angle $2 \theta=31^{\circ}$ and $45^{\circ}$. The formation of metal oxide is confirmed by the FTIR measurement. SEM study evidenced the smooth and randomly grown nanofibers with their average sizes 472 and $515 \mathrm{~nm}$ with respect to the samples BT1 and BT2 prepared at 8 and $12 \mathrm{kV}$ dc voltages. TG/DTA analysis was performed to study the heating behavior of the composite $\mathrm{BaTiO}_{3} / \mathrm{PVP}$ mat and $49 \%$ weight loss was observed at $725^{\circ} \mathrm{C}$.
\end{abstract}

Keywords: electrospinning, barium titanate, scanning electron microscopy, X-ray diffraction.

Received: 4 February 2019

Revised: 22 April 2019

\section{Introduction}

Barium titanate $\left(\mathrm{BaTiO}_{3}\right)$ has excellent ferroelectric and piezoelectric properties. This material has been utilized in several industrial applications like capacitors, actuators, non-volatile RAM etc. [1-4]. In the absence of an external field, $\mathrm{BaTiO}_{3}$ possess ferroelectric polarization. Over $\mathrm{BaTiO}_{3}$ particles, nanofibers are reported to be promising one due to their large dielectric permittivity. Electrospinning technique has been reported to be as the simplest method for the fabrication of composite nanofibers of $\mathrm{BaTiO}_{3}$. It consists of mainly three parts such as power source, collector and the syringe pump. Upon applied dc voltage, the loaded solution flows under the region of strong electrostatic field which experiences a repulsive force and as a result fine jet formed [5].

Several literature have been reported on the fabrication and characterization of $\mathrm{BaTiO}_{3}$ nanofibers by the electrospinning method [6-8]. Study of $\mathrm{BaTiO}_{3}$ nanofibers was reported after the calcination of as-prepared fiber mat at different temperatures followed by drying at $80{ }^{\circ} \mathrm{C}$ under vacuum condition [9]. The investigation by electron scanning microscopy (SEM) showed the fibers diameters from 160-300 nm. The X-ray diffraction (XRD) study endorsed the presence of tetragonal perovskite structure while Fourier transform infrared spectroscopy (FTIR) confirmed the various bonds corresponding to the $\mathrm{BaTiO}_{3}$ nanofibers. The $\mathrm{O}-\mathrm{H}$ stretching peaks at 3430 and $1425 \mathrm{~cm}^{-1}$ was found to be weak with respect to the increased calcination temperature while Ti-O peak at $570 \mathrm{~cm}^{-1}$ became strong. Remarkably, $\mathrm{BaTiO}_{3}$ nanofibers calcined in nitrogen environment could convert the tetragonal phase to cubic perovskite structure which has been attributed to the elimination of carbonate content. Electrospun fiber mats of $\mathrm{PVDF} / \mathrm{BaTiO} 3$ nanocomposites were studied [10]. By SEM analysis the prepared fibers were noticed to be well grown in random directions with diameter from $200-400 \mathrm{~nm}$. The XRD study revealed the presence of both $\alpha$ and $\beta$ phases in PVDF whereas enhanced $\beta$ phase was noticed in $\mathrm{PVDF} / \mathrm{BaTiO}_{3}$ sample. Further, the thermal emissivity was studied for both the samples and found to be reduced for the $\mathrm{PVDF} / \mathrm{BaTiO}_{3}$ sample. An approach of controlled morphology of barium titanate nanofibers has been reported [11]. The prepared nanofibers were investigated and observed to be polycrystalline in nature. The morphology was found to be ribbon-like form with their diameter and grain size 200 and $30 \mathrm{~nm}$ respectively. $\mathrm{BaTiO}_{3}$ fibrils were obtained with the increased precursor with their diameter below $50 \mathrm{~nm}$ while the morphology was the same as ribbon-like. Further, fibers calcined at temperature $700{ }^{\circ} \mathrm{C}$ were observed to be in tetragonal phase as identified by $\mathrm{XRD}$ analysis. $\mathrm{BaTiO}_{3}$ nanofibers calcined at temperature at $750{ }^{\circ} \mathrm{C}$ showed the fibers diameter from $80-190 \mathrm{~nm}$ [12]. This investigation was claimed to the stand-alone formation of ferroelectric nanofibers.

Here, we present the fabrication and characterization of $\mathrm{BaTiO}_{3}$ nanofibers prepared at two distinct dc voltages $(8$ and $12 \mathrm{kV}$ ). In Section 2, the experimental approach is presented and the obtained results are discussed in Section 3. Finally, the work is summarized in Section 4. 


\section{Experimental approach}

The chemicals, titanium-IV butoxide (TBOT), polyvinylpyrrolidone (PVP with m.wt. 1300000), barium acetate, ethyl alcohol and glacial acetic acid were procured and used without additional purification. To prepare the barium titanate $\left(\mathrm{BaTiO}_{3}\right)$ solution, the following sol-gel process was carried out. For the preparation of solution ' $\mathrm{S} 1$ ', $2 \mathrm{~g}$ barium acetate was added in $5 \mathrm{ml}$ acetic acid and kept for stirring for few minutes. Later, $3 \mathrm{ml}$ titanium (IV) butoxide was drop-wise added to the above solution and stirred for $1 \mathrm{hr}$. In a similar way, $0.5 \mathrm{~g}$ polyvinylpyrrolidone was added in $5 \mathrm{ml}$ ethanol and stirred for $30 \mathrm{~min}$ to get the solution 'S2'. Finally, both the solutions (S1 and S2) were mixed under constant stirring for few hrs. After observing the homogeneous and viscous solution, the prepared solution was loaded in syringe for the electrospinning process. The electrospinning process is summarized in Fig. 1. The drum collector was used to collect the electrospun mat while the DC voltage was applied in between the drum collector and the metal tip at room temperature while maintain humidity $40 \%$.

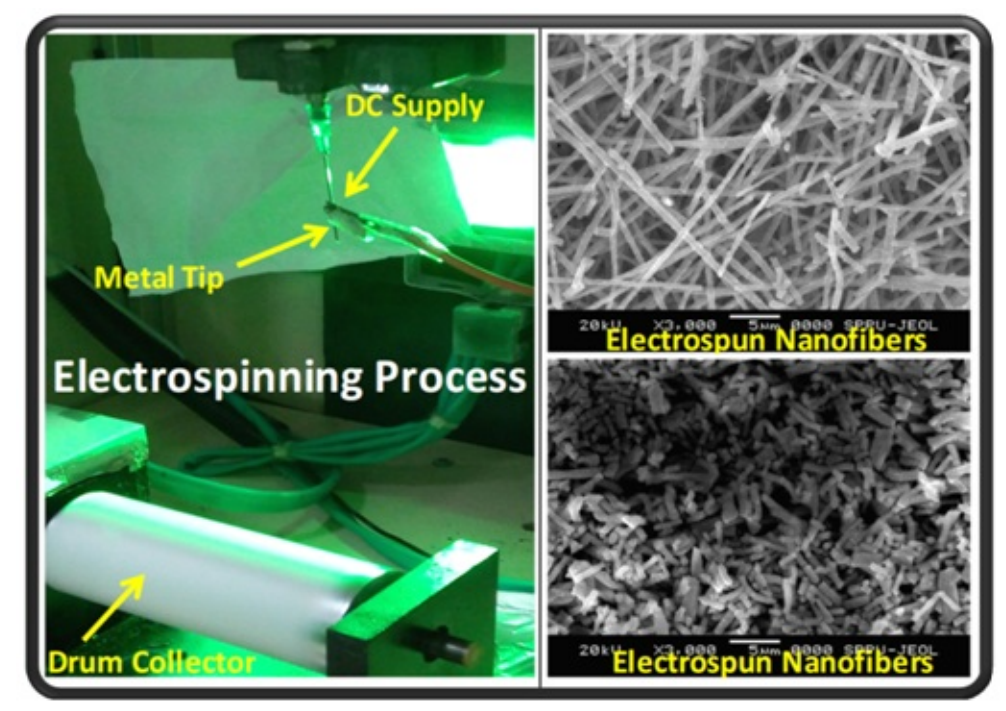

FIG. 1. Preparation of nanofibers by electrospinning method

For the preparation of nanofibers, two distinct dc voltages 8 and $12 \mathrm{kV}$ were evaluated while the solution flow rate and distance jet-collector drum were maintained to $1 \mathrm{ml} / \mathrm{h}$ and $10 \mathrm{~cm}$ respectively. After electrospinning process, the collected samples were calcined at $600{ }^{\circ} \mathrm{C}$ for $1 \mathrm{hr}$.

The samples prepared at 8 and $12 \mathrm{kV}$ voltages were named as BT1 and BT2 respectively and characterized to examine the phase and crystallinity by X-ray Diffraction (XRD-Bruker AXS D8 Advance, Germany), the qualitative and quantitative analysis by Fourier-transform infrared spectroscopy (FTIR-Shimadzu, Japan), thermal response by thermogravimetric differential thermal analysis (TG-DTA, DTG-60H, Shimadzu), the surface morphology by scanning electron microscope (SEM, JSM-6360, USA) and the elemental composition investigation by EDX attached to SEM.

\section{Results and discussion}

X-ray diffraction (XRD) patterns of samples BT1 and BT2 were recorded in the range $2 \theta=20-80^{\circ}$, which is plotted in Fig. 2. As the calcination temperature was maintained at $600{ }^{\circ} \mathrm{C}$ for $1 \mathrm{~h}$ therefore, the diffraction peaks at $2 \theta=24.1^{\circ}, 27^{\circ}, 42^{\circ}, 47^{\circ}$ and $56^{\circ}$ reveal the presence of orthorhombic phase of $\mathrm{BaCO}_{3}$ in both the samples and matched with the JCPDS\#45-1471) $[9,11]$. In addition, peaks at $2 \theta=31^{\circ}$ and $45^{\circ}$ are found to be associated with the tetragonal phase which are assigned to the planes (101) and (002) according to JCPDS\#05-0626.

To know the chemical bonds, FTIR measurements were carried out for both the samples and results are plotted in Fig. 3. The peaks at wavenumbers 3434 and $2933 \mathrm{~cm}^{-1}$ are assigned to the $\mathrm{O}-\mathrm{H}$ and $\mathrm{C}-\mathrm{H}$ stretching vibrations respectively [11].

A vibration peak corresponding to $\mathrm{C}-\mathrm{H}$ stretching can be observed from $2923-2853 \mathrm{~cm}^{-1}$ [13]. Other vibration peaks related to $\mathrm{C}=\mathrm{O}$ and $\mathrm{C}-\mathrm{C}$ can also be observed at 1634 and $1387 \mathrm{~cm}^{-1}$ respectively. For the $\mathrm{BT} 1 \mathrm{sample}$, a small peak nearly at $570 \mathrm{~cm}^{-1}$ is associated with the stretching vibration of Ti-O, however, the peak position was shifted to a slightly higher value for the case of sample BT2 prepared at increased dc voltage [13].

To investigate the morphology of $\mathrm{BaTiO}_{3}$, both samples BT1 and BT2 were characterized using scanning electron microscopy (SEM). Both the images shown in Fig. 4(a and b) depicts the uniform and homogeneous growth of $\mathrm{BaTiO}_{3}$ 


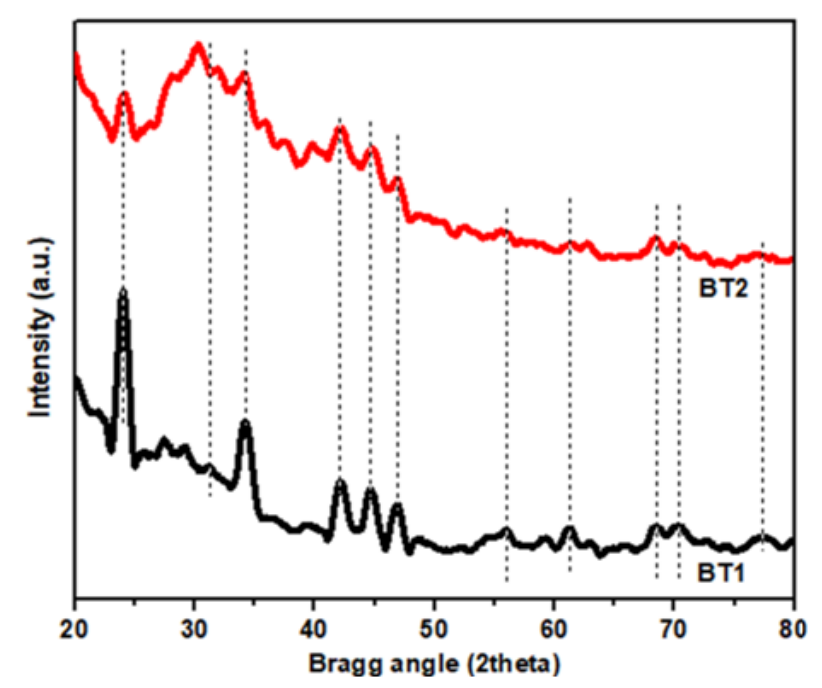

FIG. 2. XRD patterns of electrospun $\mathrm{BaTiO}_{3}$ nanofibers

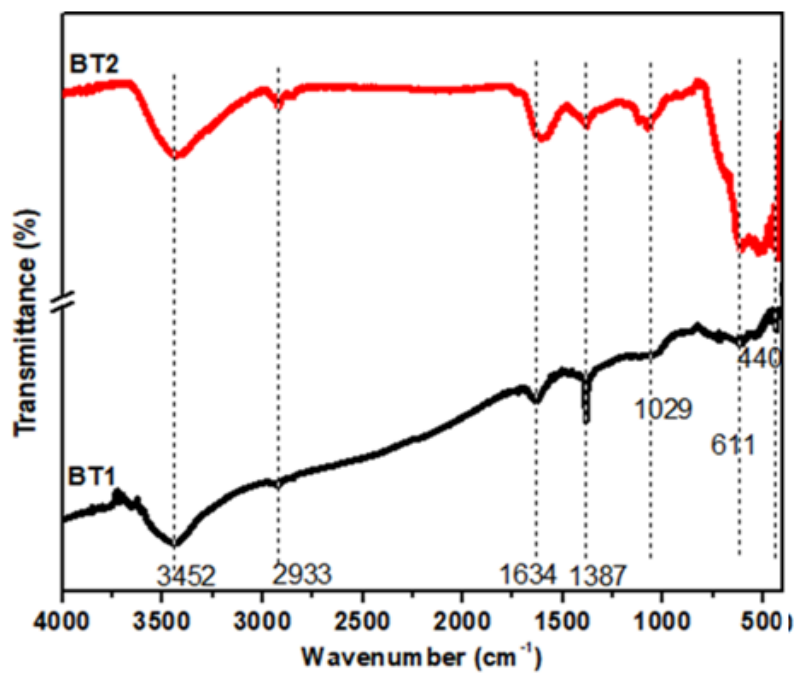

FIG. 3. FTIR spectra of electrospun $\mathrm{BaTiO}_{3}$ nanofibers

nanofibers. As compared to BT1 sample prepared at $8 \mathrm{kV}$, BT2 endorses the smooth and well aligned growth of the nanofibers. The average diameters of the BT1 and BT2 were found to be 515 and $472 \mathrm{~nm}$ respectively. The decreased diameter of the BT2 sample is attributed to the increased applied voltage which could enhance the rapid evaporation of the solvent [14].

The thermal behavior of as-prepared PVP- $\mathrm{BaTiO}_{3}$ mat was studied by thermogravimetric \& differential thermal analysis (TG/DTA) measurements which is plotted in Fig. 5. Referring to TG curve, the trend of the curve below $200{ }^{\circ} \mathrm{C}$ indicates the elimination of the water and solvent contents. Another trend of weight loss between $250{ }^{\circ} \mathrm{C}$ and $400^{\circ} \mathrm{C}$ can be observed which is regarded the decomposition of the used polymer and acetate molecules [13]. Further, the weight loss in between $600-700{ }^{\circ} \mathrm{C}$ is noticed which is associated with the decomposition of organic groups. At temperature $725^{\circ} \mathrm{C}$, the weight loss was ended with maximum of $49 \%$ of the total weight. In a similar way, DTA analysis reveals an endothermic peak at $300{ }^{\circ} \mathrm{C}$ related to the evaporation of the unwanted contents like water/solvent.

The exothermic peaks at $359{ }^{\circ} \mathrm{C}$ and $468{ }^{\circ} \mathrm{C}$ is attributed to the decomposition of barium acetate while peak corresponding to the decomposition of the main chain of PVP is also observed at $624{ }^{\circ} \mathrm{C}$. Furthermore, at $725{ }^{\circ} \mathrm{C}$ the presence of the organic groups was eliminated. 


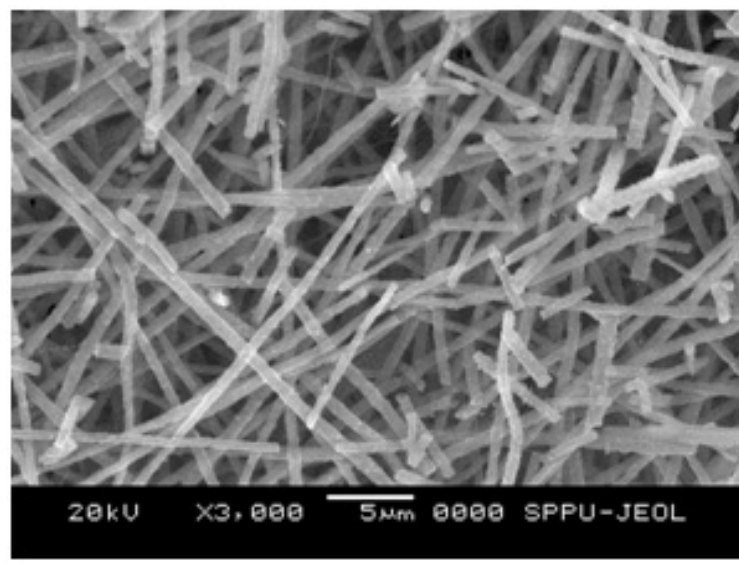

(a)

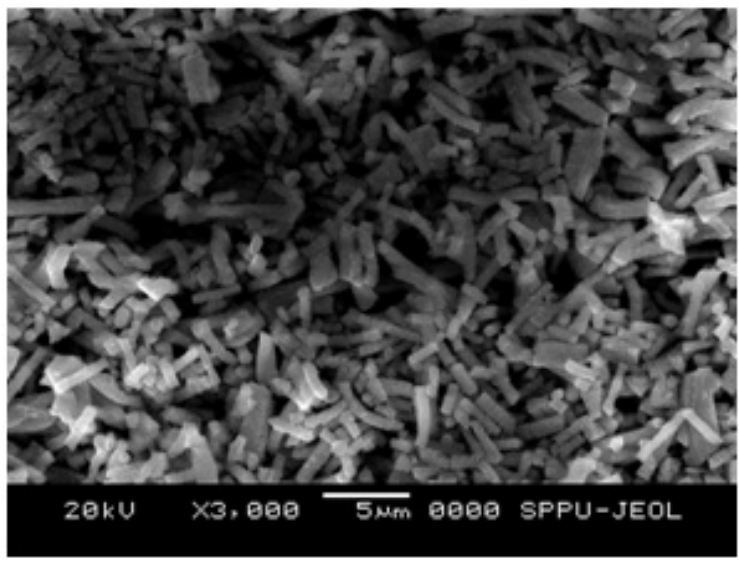

(b)

FIG. 4. SEM image of BT1 and BT2 samples prepared at 8 and $12 \mathrm{kV}$ dc voltages respectively

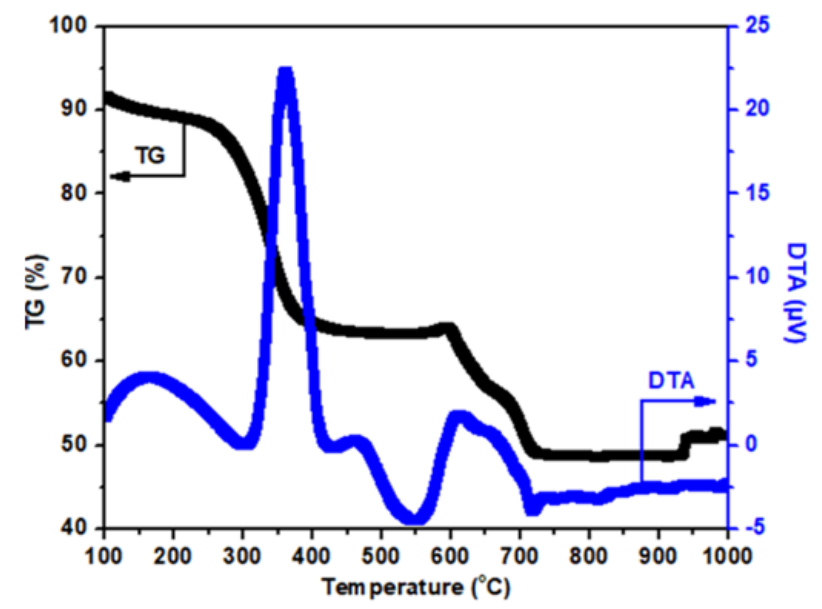

FIG. 5. TG/ DTA curves of electrospun $\mathrm{BaTiO}_{3}$ nanofibers

\section{Conclusion}

We have presented the preparation and characterization of electrospun $\mathrm{BaTiO}_{3}$ nanofibers at two distinct voltages, 8 and $12 \mathrm{kV}$. The XRD pattern endorses the formation of the tetragonal phase in both the samples BT1 and BT2. FTIR investigation showed the various vibration peaks including Ti-O bond in between $570-600 \mathrm{~cm}^{-1}$. SEM measurement evidenced the decreased diameter of the $\mathrm{BaTiO}_{3}$ nanofibers with the increased dc voltage. The TG/DTA investigation revealed the various temperature regions associated with the decomposition of $\mathrm{BaTiO}_{3}-\mathrm{PVP}$ mat and finally, the weight loss was vanished with $49 \%$ loss of the total weight at temperature $725^{\circ} \mathrm{C}$.

\section{Acknowledgements}

Authors are thankful to Prof. M. A. More (University of Pune) for the provided accessibility of the characterization facilities. 


\section{References}

[1] Ávila H.A., Reboredo M.M., Castro M., Parra R. Nanofibers obtained by electrospinning of BaTiO 3 particles dispersed in polyvinyl alcohol and ethylcellulose. Materials Research, 2013, 16 (4), P. 839-843.

[2] Zhuang Y., Li F., et al. Fabrication and Piezoelectric Property of $\mathrm{BaTiO}_{3}$ Nanofibers. J. Am. Ceram. Soc., 2014 , 1, P. 1-6.

[3] Suaste-Gomez E., Rodriguez-Montoya C., et al. Preparation of Nanoporous Fibers of $\mathrm{BaTiO}_{3}$ via Electrospinning of $\mathrm{BaTiO}_{3} / \mathrm{PVC}$ and Thermal Treatment Effects. Ferroelectrics, 2015, 482, P. 1-10.

[4] Yan Wei, Yu Song, et al. Dielectric and Ferroelectric Properties of BaTiO 3 Nanobers Prepared via Electrospinning. J. Mater. Sci. Technol., 2014, 30 (8), P. 743-747.

[5] Electrospun Nanofibers, First Edition, ed. Mehdi Afshari, Woodhead Publishing, United Kingdom, 2016,648 p.

[6] Deuk Yong Lee, Myung-Hyun Lee, et al. Effect of Calcination Temperature and Atmosphere on Crystal Structure of BaTiO 3 . Nanofibers, Met. Mater. Int., 2010, 16 (3), P. 453-457.

[7] Avinash Baji, Mojtaba Abtahi. Fabrication of barium titanate-bismuth ferrite using electrospinning. Advances in Nano Research, 2013, 1 (1), P. 183-192.

[8] Lijie Wang, Yaun He, et al. Dc Humidity sensing properties of $\mathrm{BaTiO}_{3}$ nanofiber sensors with different electrode materials. Sensor and Actuator B, 2011, 115, P. 460-464.

[9] Xiong Z.X., Pan J., et al. Preparation and properties of $\mathrm{BaTiO}_{3}$ ceramic fibers for ferroelectric applications. Ferroelectrics, 2014 , 466, P. $29-35$.

[10] Chetan Vishnu Chanmal, Jyoti Prakash Jog. Electrospun PVDF/BaTiO nanocomposites: polymorphism and thermal emissivity studies. Int. J. Plast. Technol., 2011, 15 (1), P. S1-S9.

[11] McCann T., Chen J.I.L., et al. Electrospinning of polycrystalline barium titanate nanobers with controllable morphology and alignment. Chemical Physics Letters, 2006, 424, P. 162-166.

[12] Yuh J., Nino J.C., Sigmund W.M. Synthesis of barium titanate $\left(\mathrm{BaTiO}_{3}\right)$ nanofibers via electrospinning. Materials Letters, 2005, 59, P. 36453647.

[13] Sahoo B., Panda P.K. Preparation and characterization of barium titanate nanofibers by electrospinning. Ceramics Int., 2012, 8 (6), P. 51895193.

[14] Someswararao M.V., Dubey R.S., Subbarao P.S.V., Singh S. Electrospinning process parameters dependent investigation of TiO 2 nanofibers. Results in Physics, 2018, 11, P. 223-231. 